\title{
¿LOS FALSOS MANTRAS NORCOREAMOS? DESNUCLEARIZACIÓn, COLAPSO DEL RÉGIMEN Y REUNIFICACIÓn
}

\author{
¿The false north Korean mantras? \\ Denuclearization, collapse of the regime and \\ reunification
}

\author{
Xavier Boltaina Bosch \\ Profesor de la Facultad de Derecho, Universidad de Barcelona \\ Gerente y Profesor de la Universidad Internacional Menéndez y Pelayo- sede de Cataluña \\ Secretario del Centro Español de Investigaciones Coreanas (Universidad de Castilla La Mancha)
}

2 Autor

E-mail: xavier.boltaina@ub.edu

El artículo analiza tres de la cuestiones que la mayoría de analistas e investigadores han tratado en sus documentos y monografías publicadas: la nuclearización de Corea del Norte, las perspectivas del régimen y la hipotética reunificación. En contraste con la casi totalidad de los referidos documentos, el autor plantea que la nuclearización de Corea del Norte es imparable y que una marcha atrás supondría posiblemente un gravísimo riesgo para la supervivencia del sistema norcoreano, convirtiéndose así en un elemento clave de su estrategia de seguridad militar y nacional; en cuanto al colapso del régimen, se ha vaticinado desde 1990 y no se ha concretado en el último cuarto del siglo. En este documento se analizan las razones sobre el improbable colapso y aún más, la consolidación en el poder del tercer miembro de la familia Kim; finalmente, el documento es muy crítico sobre los vaticinios de que el futuro de Corea del Norte pasa forzosamente por la reunificación con el Sur, defendiéndose que un posible futurible será la pervivencia de Corea del Norte, en un grado mayor o menor de evolución, pero en ningún caso una absorción por el Sur. De ahí que el articulo intente contextualizar y rebatir los tres mantras que hacen honor a su titulo: que Corea del Norte debe desnuclearizarse, que el régimen colapsará más pronto que tarde y que bien por ello o como proceso natural, el Norte se reunificará con el Sur, venciendo éste en el proceso.

Corea del Norte; RPDC; reunificación; desnuclearización; colapso; Kim Jong-un.

North Korea; DPRK; reunification; denuclearization; collapse; Kim Jong-un.

Resumen 
This article analyses three issues that most analysts and researches have studied in their published documents and monographs: North Korea's denuclearization, the future of the regime and a hypothetical reunification. In contrast to almost all documents mentioned, the author argues that North Korea's nuclear programme is unstoppable; in fact, its interruption would probably entail a huge risk for the survival of the North Korean system, given that it constitutes a key element of its national and military security strategy. Similarly, the collapse of the regime has been anticipated since 1990 but it has not yet been materialized during the last 25 years. In this document, the author explains the reasons for the improbability of the regime's collapse and, what is more, the consolidation of the third member of the Kim family. Finally, the document is sceptic concerning the analyses that predict that North Korea's future will inevitably entail a reunification with the South, and the article argues that the survival of North Korea is likely; the country could evolve in many ways, but never through an absorption by the South. Therefore, this article attempts to contextualize and rebate the three mantras mentioned in its title: that North Korea must give up its nuclear program, that the regime will eventually collapse and, that, as a natural process, the North will be reunified with the South, eventuating in the latter being declared as a victor.

\section{Introducción}

La República Popular Democrática de Corea (RPDC, coloquialmente conocida como Corea del Norte, para distinguirla de Corea del Sur, oficialmente "República de Corea") se encuentra permanentemente en el foco de los medios de comunicación y en el debate político internacional. Esta presencia se cohonesta mal con su tamaño e importancia política, económica y social: un país con extraordinarias dificultades económicas, sin apenas relevancia ni peso internacional, con una población de 25 millones de habitantes y con un modelo político muy singular y no homologable con el resto de sus vecinos, incluida la aun formalmente comunista China.

Y sin embargo, la RPDC es uno de los ejes centrales de la política de Asia del Este y aún más, de toda la zona de Asia-Pacífico, que implica -y complica- a las relaciones internacionales y además, hace friccionar día sí día, también las relaciones, la política y las estrategias de defensa de Rusia, China, Corea del Sur, Japón y los EE. UU., al unísono.

En las dos últimas décadas, y especialmente a partir de inicios de los 90 del pasado siglo, se han publicado un número elevado de documentos, papers, artículos e incluso numerosas monografías, generalmente en el ámbito anglosajón (EE. UU., en su gran mayoría) y en menor medida en lengua francesa, con independencia lógicamente de los estudios llevados a cabo en Corea del Sur -a propósito de Corea del Norte-y de Japón.

Todo este material, muy disperso, se basa en diferentes ejes temáticos y muy a menudo de compleja verificación en cuanto a sus conclusiones.

La RPDC es, posiblemente, uno de los Estados más opacos del mundo a la hora de transmitir información veraz o de su corroboración; los analistas, incluidos los de los servicios de inteligencia, afrontan auténticas dificultades y muros insalvables para separar la verdad de la mentira y muy a menudo, las especulaciones son el eje central de muchos documentos que pueden consultarse y la verificación de aquéllos más que dudosa.

Irónicamente podemos destacar que sobre Corea del Norte se puede afirmar una cosa y su contraria sin ningún tipo de rubor, todo ello sin perjuicio de que los medios de comunicación 
puedan publicar cualquier noticia, por surrealista y estrafalaria que sea, que es creída por el público, aunque resulte a todas luces falsa ${ }^{1}$.

Así, el interesante estudio llevado a cabo por Max Nurnus y Maël Van Beeik (2015) sobre los estereotipos que la prensa británica, francesa y alemana reproducen sobre Corea del Norte, lleva a conclusiones curiosas, porque suponen una clara aproximación al régimen de forma peyorativa, sin localizarse reflexión positiva alguna, de tal manera que sobre casi 1.300 artículos analizados editados por seis grandes periódicos, el 50 por ciento se refiere al régimen como dictatorial, el 30 por ciento a su carácter beligerante, el 25 por ciento a su "carácter ridículo", el 25 por ciento al colapso que sobrevendrá inevitablemente, el 17 por ciento a su potencial amenaza, el 11 a los derechos humanos, el 10 por ciento a las crisis humanitarias, el 10 por ciento destaca su carácter "enigmático” y el 8 por ciento a su relación con China².

El estudio de Corea del Norte, en el ámbito estrictamente científico sin embargo, se ha centrado mayoritariamente en aspectos en donde el investigador puede teorizar sin una necesidad de comprobación o verificación in situ, dada la práctica imposibilidad del estudio personal sobre el terreno de los asuntos más espinosos.

Así, una multiplicación exponencial de publicaciones y documentos han visto a la luz especialmente en los últimos diez años por parte de investigadores, académicos, analistas y profesores que o bien jamás han visitado el país - ¿es posible analizar y teorizar sobre un país que no se ha visitado?-, o lo han hecho fugazmente en estancias de máximo 7 o 10 días -con el riesgo de extrapolar datos puntuales a la categoría de generales, sin mayor rigor, y quizá más riesgo que el que jamás ha visitado el país-y en base a datos generalmente no contrastables.

A ello se ha unido una pléyade de periodistas que tras su corta visita al país han publicado su libro de rigor, repitiéndose unos y otros y generalizando lo que el ojo observador ha podido ver a golpe de pájaro tras los cristales de su autocar o coche, escoltado siempre por el guía, el traductor y el conductor. En España este género bibliográfico lo inicio Roger Mateos (2008), quizá el libro más solvente aun tratándose del género periodístico, seguido luego por otros muchos basados en cortos viajes y la reiteración de los manidos lugares comunes ${ }^{3}$.

Igualmente, un cúmulo de libros se ha publicado de la mano de exiliados o ciudadanos que han huido de Corea del Norte, traducidos en parte al castellano. Así, las monografías de Kim Suki (2015), Wizenberg y Varsavsky (2016), Park Yeon-mi (2017), Lee Hyeonseo (2015), Lee Euna

1 Buena prueba de ello han sido los rumores sobre la ejecución de una exnovia de Kim Jong-Un. Según ello, fue detenida en julio de 2013 junto al resto de componentes de la orquesta Unhasu y ejecutadas todas ellas, acto que fue presenciado por los familiares, que a continuación fueron deportados, se supone, a campos de concentración bajo la acusación de "culpa por asociación" (informaciones del diario Chilbo, de Seúl), noticia que jamás fue verificada; Vid., www.abc.es/internacional, consulta de 7-1-2014. Más impactante fue la noticia sobre la surrealista ejecución del general Jang, presuntamente lanzado a una jauría de 150 perros ante la presencia de público afecto al régimen -luego desmentida por tratarse de una broma de un "bloggero" pero que no fue contrastada por los medios occidentales- pese a la dudosa fuente basada en un periódico de Singapur que había tomado la noticia de un tabloide de Hong-Kong.

2 La versión original del estudio se presentó en el tercer congreso de política y sociedad coreana, celebrado en agosto de 2015 en Gyeongju, Corea del Sur. Muchos de los 1.300 artículos analizados engloban dos o más de las calificaciones porcentualizadas.

3 Véase Pitarch (2012). De la pluma de Cao de Benós (2013), ciudadano español presidente de la Korean Friendship Association y habitual en los medios de comunicación, puede consultarse Alma Roja, sangre azul, Editorial Base Hispánica. Aunque ya sea en el panorama internacional, es interesante el cómic del dibujante canadiense Delisle (2013), Pyongyang, que ha sido calificado como "el mejor documental que se ha hecho sobre Corea del Norte en una historieta" -afirmación que matizaríamos en alguna medida-, reeditado en español hasta en doce ocasiones (la última, en 2013).

\section{El estudio de Corea del norte se ha centrado mayoritariamente en aspectos en donde el investigador puede teorizar sin una necesidad de comprobación o verificación in situ}


(2011) y Shin Dong-hyuk (2014) que aportan una visión personal sobre su vida y las razones que les llevó a huir de Corea del Norte y, quizá en la parte más significativa, las dificultades de su integración en la sociedad surcoreana y que tienen el valor -y las cautelas- del género del testimonio personal, tan importante por lo demás para el conocimiento de determinados momentos históricos donde no hay documentos o datos primarios contrastables ${ }^{4}$.

Por lo demás, la inmensa mayoría de los documentos que pueden consultarse parten de una óptica absolutamente occidental (Europa, EE. UU. y Australia, en especial) o bien tiene su origen en Corea del Sur -formalmente el "enemigo” de Corea del Norte- o Japón. Frente a la lejanía cultural de la primera perspectiva -y por la general con clichés predeterminados-, la segunda está sesgada y muy mediatizada por razones de seguridad nacional (caso de Corea del Sur) o de pasado histórico; así, Japón, con cuentas pendientes con Corea del Norte, pues es acusado por ésta de no haber reparado aún sus crímenes de guerra y contra la humanidad llevados a cabo durante el periodo 1910-1945 en que ocupó la península5.

En este debate tan complejo se une, además, la permanente belicosidad del régimen norcoreano, en una espiral permanente de discurso inicial, replica, duplica frente a EE. UU., Japón y Corea del Sur, fundamentalmente, pero también con relaciones complejas con el que se considera su gran "aliado", la República Popular China, como lo acredita el comentario del mes de mayo de 2017 del Rodong Sinmun ${ }^{6}$, que lanzó una sorprendente crítica a China por no darle suficiente apoyo en su programa militar nuclear.

Sin ánimo de generalizar, diversas son las temáticas que nutren un porcentaje muy elevado de los documentos, ponencias, comunicaciones y monografías sobre Corea del Norte disponibles. Éstas se centran, en casi dos terceras partes, en tres ejes, muy queridos para el investigador y los círculos académicos: la nuclearización del régimen, el hipotético colapso de Corea del Norte y la reunificación con el Sur.

Otros temas tratados con menor reiteración son la situación de los derechos humanos, la economía - por lo habitual vinculándola al hipotético colapso del régimen- o relatos de viajes generalmente en este caso -como hemos indicado- escritos por periodistas.

Un ámbito muy específico -y muy abundante en monografías y documentos- es el militar, incluso con webs exclusivas dedicadas al tema, si bien mayoritariamente se confunden en su

4 La experiencia de Shin Dong-hyuk, que huyó del Campo de concentración nr.14, es relatada en Harden (2014); la experiencia de un cautiverio en Corea del Norte de una reportera de televisión norteamericana en Lee (2011); sobre la huida de una muchacha norcoreana, Lee (2015); en el mismo sentido, Park (2017); el libro de Kim (2015) narra la experiencia de una profesora norteamericana nacida en Corea del Sur que durante unos meses impartió docencia en un centro de élite de Pyongyang. Recientemente, las crónicas sobre un viaje al Norte y al Sur de dos argentinos en Wizenberg y Varsavsky (2016). En general experiencias personales reiteradas y que en no pocas ocasiones no podemos compartir por nuestra propia experiencia, al ser exageraciones o distorsiones o planteamientos muy difusos elevados a categoría general.

5 Para una buena panorámica del periodo militarista japonés de la segunda mitad del siglo XX, véase Rees (2009).

6 Rodong Sinmun, órgano del comité central del Partido del Trabajo de Corea, de 5 de mayo de 2017: "Reckless Remarks Undermining DPRK-China relations should be stopped", que acusa a China de falta de sinceridad e incluso de traición y en donde se refleja finalmente que China no puede poner límites a la paciencia de Corea del Norte y que la "amistad" entre los dos países de nada servirá si se desea eliminar el programa nuclear norcoreano, considerado "tan valioso como la propia vida". El artículo es firmado por un desconocido Kim Chol, al que los servicios de inteligencia extranjeros le atribuyen que es posiblemente un inexistente comentarista -bajo seudónimo- que refleja el criterio del régimen norcoreano.

\section{La inmensa} mayoría de los documentos que pueden consultarse parten de una óptica absolutamente occidental 
contenido en el primero de los ejes, la nuclearización de la RPDC, pues este proceso no va unido a fines civiles sino a un elemento ofensivo/defensivo militar ${ }^{7}$.

Nuestro objetivo es establecer unos parámetros distintos a los habituales. Deseamos apuntar algunos elementos para cuestionar el discurso académico y analítico al uso, el mantra sobre estos tres aspectos primeros antes citados, asumidos generalmente de forma casi monopolística como ciertos, cuando hay elementos importantes que los desvirtúan o incluso invalidan.

Un mantra es una palabra sánscrita que se refiere a sonidos (sílabas, palabras, fonemas o grupos de palabras) que, según algunas creencias, tienen algún poder psicológico o espiritual. En la psicología, el término «mantra» se utiliza como figura retórica para significar la repetición neurótica del sujeto a fin de fijar y reforzar un pensamiento circular. Entre los "norcoreanólogos", algunos mantras han pasado a ser tan intensivamente reiterados que merecen una consideración in extenso. Con fina ironía pero con gran certeza, el periodista Carlos Manuel Sánchez definió a los "norcoreanólogos" como "la tribu más extraña de las que pululan por los servicios de inteligencia y los ministerios de Exteriores”, a lo que añadiríamos también desde el ámbito de las Universidades ${ }^{8}$.

El primer mantra es que Corea del Norte en ningún caso puede tener programa nuclear ni desarrollar armas de este tipo y que el mantenimiento de esta postura supone un riesgo para la seguridad de la zona y del mundo y que, por lo tanto, debe frenarse a cualquier precio su nuclearización.

El segundo mantra es que Corea del Norte colapsará como régimen y se hundirá irremediablemente, ya sea de manera repentina o progresivamente, pero que su itinerario vital futuro es ya corto y en todo caso imposible de prolongarse en el tiempo. Mantra que desde 1990 se predice y sigue manteniéndose de forma mayoritaria.

El tercer y último mantra pasa por establecer que el itinerario histórico futuro de las dos Coreas pasa, inevitablemente, por su reunificación y, aún más, con la victoria del modelo del Sur que incorporará, por absorción repentina o progresiva al Norte, liquidando al régimen actual de Pyongyang y logrando un total control de la península bajo un modelo capitalista prooccidental y el final del sistema neocomunista de la RPDC.

Para nuestro análisis, se hace preciso tener en cuenta la posición de la contra parte -en este caso, Corea del Norte- que en los análisis es ignorado o minusvalorado, por razones muy diversas, incluso llevado al extremo del absoluto desprecio o descalificación, que impiden al analista ser riguroso porque más allá de posicionamientos ideológicos o de empatía/antipatía hacia el régimen, obvian la determinación del gobierno de Pyongyang en su deseo absoluto de supervivencia, a toda costa, objetivo que ha logrado desde 1945 y especialmente desde su proclamación como república independiente en 1948.

7 La web www.38north.org es posiblemente en el momento actual la que mejor refleja la evolución militar y especialmente nuclear defensiva/ofensiva de Corea del Norte. 38 North es un think tank del U.S.-Korea Institute at SAIS (USKI) dirigido por Joel S. Wit, exfuncionario del Departamento de Estado de los Estados Unidos y actual Visiting Scholar de USKI, y Jenny Town, subdirectora de USKI. 


\section{El primer mantra: la nuclearización vs desnuclearización}

Se trata de una de las cuestiones más extensa e intensivamente tratada y que va unida también a la situación militar del vértice China/Corea/Japón y los EE. UU. Frente a la voluntad norcoreana de lograr y desplegar el arma nuclear, el resto de países, incluso aliados, le niegan esta opción, pese a que China y EE. UU. la poseen y que Corea del Sur y Japón cuentan con una vasta red de centrales nucleares ${ }^{9}$.

Desde el mismo fin de la guerra de Corea de 1950-1953, no ha habido momento de descanso en las fricciones constantes entre Corea del Norte y sus vecinos, así como con los EE. UU., como destaca el incidente del barco USS Pueblo ${ }^{10}$.

Esa misma guerra fue de resultados atroces en términos de vidas humanas y de destrucción económica (33.000 soldados norteamericanos fallecidos, 100.000 heridos de igual nacionalidad, más 1,5 millón de fallecidos de nacionalidad norcoreana y china ${ }^{11}$ ), una guerra estéril y absolutamente inútil, pues no supuso ninguna victoria real para ninguno de los bandos y el inicio de la cronificación de la división ${ }^{12}$ que se mantiene (2017) durante ya 72 años.

Desde ese mismo momento, y en plena Guerra Fría, Corea del Norte optó por una estructura militar de su régimen, lo que llega a su máximo exponente a partir de 1994 con la asunción del poder de Kim Jong-il, hijo del fundador de la República, Kim Il-sung. La opción militar de Kim Jong-il, que incorpora su modelo militarista a través de la Idea "Songun" parece a ojos del régimen inevitable, por las razones que señalamos a continuación y que en gran parte se mantienen en el momento presente bajo el régimen de Kim Jong-un.

a) Corea del Norte observó impotente cómo se derrumbó el bloque soviético y sus aliados más o menos permanentes como la URSS y los países comunistas, así como los cambios irreversibles de sus aliados asiáticos, China y Vietnam.

El fin de la Unión Soviética implicó el fin de una ayuda imprescindible para el país y un aislamiento brutal en términos políticos, económicos y de relaciones internacionales que solo superó con la ayuda de China y con una decisión importante: transformar la ideología del país -oficialmente denominada Juche, una evolución nacionalista norcoreana del marxismo-leninismo- en un salto adelante, denominado el pensamiento "Songun", expresión

9 La primera central nuclear surcoreana data de 1972 y en la actualidad mantiene unos 24 reactores en activo, los dos últimos inaugurados en noviembre de 2015. Japón posee 53 centrales que generan el 35 por ciento de la electricidad del país.

10 El USS Pueblo es un buque estadounidense para operaciones de inteligencia militar que fue capturado por las fuerzas de Corea del Norte en enero de 1968, en el hecho conocido como Incidente del USS Pueblo o también como Crisis del USS Pueblo. La captura ocurrió una semana después de que el presidente Lyndon B. Johnson pronunciase su discurso del Estado de la Unión en el Congreso, y una semana antes del inicio de la Ofensiva del Tet; siendo junto al subsiguiente encarcelamiento de la tripulación por las autoridades norcoreanas durante once meses un incidente muy importante de la Guerra Fría. Corea del Norte afirmó que el USS Pueblo se encontraba en sus aguas territoriales al momento de ser capturado, negado por EE.UU. El USS Pueblo, aún en poder de Corea del Norte, oficialmente figura en la nómina de la Armada de los Estados Unidos como buque asignado en activo. Estuvo amarrado en el río Taedong en Pyongyang y actualmente en el Museo de la Guerra. El USS Pueblo es el único buque de la Armada de Estados Unidos que permanece capturado. Puede visitarse en el Museo de la Guerra de Pyongyang, dedicado al conflicto de 1950-1953.

11 Estos son los datos más próximos a la realidad que se facilitan en la obra de Halberstam (2007).

12 Entre la bibliografía más reciente, en castellano, véase Halberstam (2008), traducción de la monografía señalada en el pie de página anterior. Un referente literario, en forma de novela, con una visión crítica sobre la manipulación informativa occidental de la guerra, es el clásico de 1964 de Kim (2014).
La opción militar de Kim Jong-il, que incorpora su modelo militarista a través de la ldea "Songun" parece a ojos del régimen inevitable 
coreana que se refiere a la priorización de los asuntos militares en todos los aspectos de la sociedad o "military first policy"13.

b) La inmensa mayoría de los analistas ha criticado este militarismo de Corea del Norte, que le ha llevado a mantener en activo unas fuerzas armadas de 1,1 millón de efectivos -para un población de 25 millones de habitantes- en un territorio de $120.000 \mathrm{~km}^{2}$, más una fuerza reservista seis veces más numerosa, si bien quizá el uso del ejército para tareas económicas y sociales -mantenimiento de infraestructuras, conservación de bosques, suministro de alimentos a las zonas rurales, labor pura y dura de construcción- permitió sobrevivir al desastre humanitario del 1994-1998.

La RPDC, sin embargo, no ha abjurado en absoluto de esta opción "militar-social"; ha elevado la idea Songun a componente ideológico plasmado en la Constitución y en todos y cada uno de los discursos de sus líderes, cuanto menos hasta finales del régimen de Kim Jong-il. Se discute ahora si su sucesor, Kim Jong-un -hijo del anterior y nieto de Kim Ilsung- plantea o no un cambio de estrategia, pero siendo aún muy temprano para llegar a una conclusión, lo cierto es que el papel de las Fuerzas Armadas en Corea del Norte es clave para entender el "paradigma norcoreano" y también para interpretar el futuro del régimen ${ }^{14}$.

c) En este esquema, hay un elemento también que aparece de manera constante y que el régimen en modo alguno oculta: la nuclearización militar del país. Corea del Norte, a diferencia de otros países que defienden un programa nuclear con fines pacíficos para obtener energía -de hecho, su "enemigo", el Sur, posee 25 centrales nucleares-, no niega en absoluto que ha buscado, y que sigue haciéndolo, el arma nuclear con fines no solo defensivos sino también ofensivos y en modo alguno se refiere al uso civil de la energía nuclear.

Posiblemente es el país "menos hipócrita" en estos términos: no niega que el arma nuclear es elemento clave en su desarrollo y supervivencia y está dispuesta a usarla, en una retórica quizá poco creíble en vista de los enemigos a los que se enfrenta, especialmente EE.UU., pero que nos permite plantear que ese elemento, incluso elevado a rango constitucional, constituye la construcción de un pensamiento "nacionalista” nuclear en Corea del Norte ${ }^{15}$,

13 El ejército norcoreano y su programa militar convencional y nuclear es extraordinariamente difícil de estudiar, con fuentes contrastadas. El aspecto ideológico del papel de sus fuerzas armadas y de la Idea Songun ha sido expuesto por diversos documentos de los diferentes líderes máximos que ha tenido el país, especialmente el fallecido Kim Jong-il, que fue quien integró la Songun en su línea política a partir de 1994. Especialmente sobre el aspecto ideológico de la Idea puede consultarse de Kim Il-sung, The selected Works of Kim Il Sung, editor Prism Key Press (versión en amazon/kindle, de 2012); igualmente, publicado por el régimen Preguntas y respuestas sobre la idea Songun, en castellano, Foreign Language Publications House of Pyongyang (2012) consultable en línea; y de Dermont Hudson (2016), In defence of Songun, lulu.com. De próxima aparición, de los autores Stijn Mister y Joost Oliemans, sobre las Fuerzas Armadas norcoreanas, North Korea's Armed Forces: on the Path of Songun, Ed. Helion \& Company, prevista para 2018. Hasta el momento, la mejor monografía, pese a su antigüedad (2001) es The Armed Forces of North Korea, de Joseph S.Bermudez, Ed. I.B.Tauris. Bermudez Jr, es un riguroso analista, especialista en temas militares norcoreanos. Fue analista senior de Digital Globe’s Análisis Center. Ha publicado más de 100 artículos, informes y monografías sobre la cuestión, incluso sobre los sistemas de inteligencia y contrainteligencia norcoreana en North Korean Intelligence 1945-1980.

14 Véase, al respecto, Office of the Secretary de Defense (2015).

15 El régimen no oculta en modo alguno el objetivo del arma nuclear en constantes editoriales publicados en Rodong Sinmun, aún más en los dos últimos años (2016 y 2017) sin que el uso civil del arma aparezca como una referencia cuanto menos autojustificativa.

\section{Posiblemente es el país "menos hipócrita" en estos téminos: no niega que el arma nuclear es elemento clave en su desarrollo y supervivencia}


concepto terminológico que empieza a abrirse paso también entre los analistas militares (Péron-Doise, 2016 ${ }^{16}$ ).

Pero en esta ausencia de hipocresía, hay un elemento clave: la nuclearización de Corea del Norte es un proceso querido por todos sus tres máximos dirigentes desde hace ya cuatro décadas y Kim Jong-un ha fortalecido aún más este proceso.

El primer mantra al cual nos referimos en el título de este documento es que a juicio de todos, incluida su "aliada” China, la nuclearización de Corea del Norte es negativa y que su programa nuclear debe finalizar y desaparecer y que ninguna gran potencia de la zona puede permitir que el país disponga de armas nucleares. Al respecto, el análisis se basa en algunos elementos fundamentales:

En primer término, Corea del Norte -en este discurso generalizado- no puede poseer armas nucleares per se, sin más razón de que ello es pernicioso para la paz y la seguridad de la zona y del mundo, máxime cuando el régimen amenaza abiertamente en su discurso oficial con atacar incluso los EE.UU.

Sin lugar a dudas ello es así -en cuanto al peligro del arma nuclear-, pero ello también es el ritual discursivo que podría aplicarse a otros países que sí poseen armas nucleares, especialmente EE.UU., pero otros mucho más inestables como Pakistán o la India.

Naturalmente, el armamento nuclear es un elemento extraordinariamente peligroso en cualquier parte del planeta, sea Pakistán, Israel, Francia, Reino Unido, Rusia, China, EE.UU. o Corea del Norte. Ello sin tener en cuenta que no son pocos los analistas que indican que la prohibición de armas nucleares abriría, hoy en día, la puerta a la búsqueda de otra arma, quizá más peligrosa ${ }^{17}$.

Sin embargo, a la RPDC se le niega este derecho - criterio que podemos aceptar- pero no se añaden otros elementos que consideramos significativos, no siendo menor el que ninguna de las potencias nucleares actuales tiene intención de reducir su capacidad nuclear, sino acaso adaptarse a los nuevos tiempos y modernizar su armamento y otros vectores colaterales (Petrovic, 2017).

Así, frente a Corea del Norte, el Sur mantiene unas fuerzas armadas convencionales altamente profesionales y efectivas y de gran nivel y calidad, con 855.000 soldados y la presencia de tropas norteamericanas en el territorio.

Sus fuerzas terrestres cuentan con 522.000 efectivos y el servicio militar obligatorio es de casi dos años; la fuerza aérea surcoreana comprende 600 aviones de combate, casi todos

16 Marianne Péron-Doise, investigadora de Asia del Norte del Institut de Recherche stratégique de l'Ecole Militaire de la France, en Corée du Nord : l'impossible dénucléarisation (documento de trabajo de 10-10-2016), afirma que el arma nuclear es un factor importante de legitimación interna del régimen de Kim Jong-un y que ante la imposibilidad de satisfacer todas las necesidades de la población, ideológicamente el arma nuclear permite mantener a distancia a la superpotencia americana y a Corea del Sur, en un especie de "ferocidad nacional", ampliamente explotada por la propaganda interna. Así, el ensayo nuclear de 2006 se lee internamente como un desafío a la Administración Bush, tras la invasión de Irak y la ejecución de S. Hussein y obligó a EE.UU. a mantener una postura más conciliadora, lo que no ha disuadido a Corea del Norte para un segundo ensayo nuclear en 2009 a fin de obtener el mismo trato con la nueva Administración Obama, que planteó la calificada como "paciencia estratégica". A nuestro juicio, el nuevo envite agresivo de Pyongyang en 2017 supone marcar de nuevo las líneas rojas con la Administración Trump.

17 Como Petrovic (2017), informático e historiador experto en armas nucleares.

\section{Mo son pocos los analistas que indican que la prohibición de amas nucleares abrina, hoy en día, la puerta a la búsqueda de otra ama, quizá más peligrosa}


ellos de origen norteamericano de moderna o última generación ${ }^{18}$. También residen permanentemente 30.000 soldados norteamericanos, que se unen en esa zona "caliente" a las 32 bases militares con 25.000 soldados estacionados en Japón.

A ello se añade que todos los años, especialmente en abril-mayo, se celebran frente a las costas norcoreanas gigantescas maniobras conjuntas aeronavales de EE.UU. y Corea del Sur, denominadas Foal Eagle y Key Resolve ${ }^{19}$ a lo cual el Norte responde generalmente con el lanzamiento de diversos cohetes o misiles o hace explosionar armas nucleares en pruebas para ir avanzando en su proceso.

En segundo lugar, excepto China y Rusia, ninguno de los países que critican el programa norcoreano mantiene relaciones diplomáticas con el país. El intercambio de pareceres en ocasiones es casi nulo y tras la llegada de Donald Trump a la presidencia, el diálogo es un enfrentamiento abierto aunque tampoco exento de fricciones con el Sur, nada predispuesto a un ataque militar contra el Norte por las consecuencias económicas y humanitarias que supondría.

d) El análisis más convencional olvida que en el discurso político y en la estrategia militar norcoreana el arma nuclear es, de forma casi exclusiva, un elemento de garantía de supervivencia. En los documentos públicos del régimen de Pyongyang aparece claramente referenciado que los países árabes o Yugoslavia fueron bloqueados por sus "enemigos" por no poseer armas de destrucción masiva, una perspectiva que Corea del Norte no desea en absoluto reproducir.

Por consiguiente, el arma nuclear tiene, en el régimen norcoreano, un elemento, un plus, más elevado que en el resto de países, que no es novedoso sino que tiene su propio origen en los primeros tanteos para poseer el arma nuclear que se retrotraen a 1962 y la negativa soviética de 1963 de ayudar a la república de Kim Il-sung en su objetivo de poseer armas, lo que no les desalentó pues el programa strictu sensu se inició en $1980^{20}$.

Así, el arma nuclear no es para Francia, Reino Unido, Rusia o E.UU. un elemento de supervivencia. Incluso en el resto de países que lo poseen (Pakistán, India), el arma nuclear aparece como un elemento de garantía, con una única excepción, Israel.

Claro está que Israel es un país democrático rodeado de regímenes militares, teocráticos o colapsados (Egipto, Siria, Líbano) que en el peor de los supuestos desean su total desaparición (Irán), por lo que el programa nuclear israelí tiene un componente de supervivencia clarísimo. Muchos analistas parecen olvidar que éste es el esquema estratégico seguido por Corea del Norte, pese a que en aquel primer caso estamos ante una democracia civil y en la RPDC en un sistema totalitario, pero la reflexión es idéntica: para Corea del Norte el arma nuclear es

18 Los datos actualizaos figurarán en http://globalsecurity.org/military/world/rok/index.html

19 En las maniobras de abril de 2016 intervinieron 300.000 soldados surcoreanos y 15.000 norteamericanos, las mayores en despliegue de toda la historia.

20 Numerosa literatura ha tratado sobre el programa nuclear de la RPDC. En cuanto a su perspectiva vinculada a la supervivencia del régimen kimilsungnista y de sus sucesores, podemos destacar a Bracken (1993). En el 2003, fallecido ya Kim Il-sung y en el poder su hijo Kim Jong-il y en pleno auge de la teoría Songun, vid. Morton I. Abramowitz y James T. Laney en Meeting the North Korean Nuclear challenge (2003), en Council on Foreing Relations, USA. Poco antes de fallecer Kim Jong-il, un clásico de la literatura académica es Daniel Byman y Jennifer Lind (2010) Pyongyang's survival strategy. International Security, 35 (1) 44-74. Entre los documentos más recientes (2017), destacaremos a John K. Warden en North Korea's nuclear posture an evolving challege for US Deterrence, num.3/2017, en Proliferation Papers, HRI, Security Studies Center.

\section{Excepto China y Rusia, ninguno de los países que critican el programa norcoreano mantiene relaciones diplomáticas con el país}


una garantía de supervivencia, el eje central para evitar un ataque contra el país que bloquee su estructura y destruya su capacidad de respuesta, que no la tiene en armas convencionales, pues su ejército actual es inoperativo.

Aunque en muchos documentos que pueden consultarse en abierto se da por supuesto que el arma nuclear norcoreana es un elemento de "supervivencia" del régimen, no parece darse clara importancia a ese "nacionalismo" nuclear.

Corea del Norte no puede seguir manteniendo un esquema de gasto en términos de PIB del 16 por ciento -que algunos analistas elevan al 20 o 25-. El Sur gasta porcentualmente mucho menos, pero las economías no son parejas.

El PIB de Corea del Sur se situaba en 2008 en 680.000 millones de euros, pasando a 983.000 millones en 2013 y alcanzando el 2016 los 1,274 billones de euros, lo que acredita una velocidad de crucero impresionante. La renta per cápita ha pasado de 13.882 euros en el 2008 a 25.000 euros en el $2016^{21}$.

Por el contrario, el PIB de Corea del Norte se sitúa entre los 11 y los 13 mil millones anuales ${ }^{22}$ y un posible PIB per cápita de 300 euros anuales. Como datos de contraste, hemos de indicar que el PIB español del 2016 fue de 1,11 billones y que para comparar con Corea del Norte señalaremos que su PIB sería parecido al de la provincia de Valladolid (12.984 millones) o Córdoba (12.984 millones) e inferior a Almería, Granada o Pontevedra. Uno de los países más pobres de Asia, como es Laos, con una población más de 3 veces inferior a la RPDC, goza del mismo PIB que Corea del Norte.

El gasto en defensa de Corea del Sur (datos de 2015) supuso 32.828 millones de euros, es decir casi el 11 por ciento de su gasto público total y el 2,64 de su PIB, situándose a nivel mundial en el puesto número 10 en términos de inversión absoluta, correspondiendo a 644 euros por habitante (en el 2014 era de 553 euros). En términos de gasto público, Corea del Sur había llegado a alcanzar el 14 por ciento en el 2010.

Por el contrario, si tomamos como ciertos los datos facilitados por Corea del Norte (2016), el presupuesto de defensa norcoreano supone el 16 por ciento, en base a los Presupuestos Generales aprobados para ese año ${ }^{23}$.

Sin embargo, el porcentaje no es lo significativo, sino en términos de gastos y PIB. Aunque algunas voces indicaban en el 2009 que el gasto real era 15 veces superior al oficial -según el KIDA, Instituto de Análisis de Defensa del Sur-, se situaría a principios de la actual década en 6.594 millones de euros -aunque el régimen solo reconocía 429 millones, lo que supondría superar el 23 por ciento del PIB-24.

21 Obtenido de smacro.com/pib/corea-del-sur" http:/www.datosmacro.com/pib/corea-del-sur

22 Gay de Liébana (La Vanguardia, 26-5-2017) tras situar la economía norcoreana como una incógnita, la calificó de débil y situaba el PIB de Corea del Norte, según cifras del 2013, en algo menos de 13.000 millones, en una economía autárquica y autosuficiente, con una agricultura para consumo propio. En BTI 2016 North Korea Country Report, no aparecen datos contrastados de los últimos años.

23 Corea del Norte dedicará a defensa un 15,8 por ciento del presupuesto estatal de este año, en tanto que a industria se dedicó el 4,8 por ciento, 4,3 a la agricultura, 6,9 a la pesca, 7,5 a los bosques y 13,7 por ciento a infraestructuras. Datos extraídos de las informaciones oficiales publicadas en Rodong Sinmun y Naenara, en marzo de 2016.

24 En Paralelo 38: Corea del Norte, sola contra todos (2017), en Estudios de Política Exterior (abril, 2017), haciéndose eco del Departamento de Estado de EE.UU., para el 2016 el porcentaje sería el 15,8 por ciento del presupuesto; sería en torno a 6.500 millones de dólares, lo que supera el 23 por ciento.

Si tomamos como ciertos los datos facilitados por Corea del norte, el presupuesto de defensa norcoreano supone el 16 por ciento 
Aun siendo cierto ese primer dato, debe anteponerse a los 32.828 millones de euros de Corea del Sur y teniendo en cuenta que en el caso del Norte, la cifra se iría, fundamentalmente, en gastos de sueldos y mantenimiento de la infraestructura y no a la compra de material convencional, con muy dudosa compra de material en el extranjero ${ }^{25}$.

Para Corea del Norte el arma nuclear -así como la química y bacteriológica- es una opción de supervivencia mucho más liviana y de increíble mejor retorno en términos de gasto económico; igualmente comporta un temor más elevado: Seúl se sitúa a $55 \mathrm{~km}$ de la frontera y aunque un ataque norcoreano preventivo sería demoledor para el país -el contraataque implicaría el fin del Estado- también es cierto que un ataque preventivo de EE.UU. o de Corea del Sur al estilo de Siria, Afganistán o Yugoslavia, podría poner en pie de guerra no solo a 1,1 millones de soldados - mal dotados y con armamento envejecido, eso sí- pero también dar paso a una respuesta desconocida, porque ningún analista es capaz de prever ciertamente hasta donde el régimen de Pyongyang sería capaz de llegar si prevé el colapso final y desea evitar un fin de su nomenklatura como el referente de Irak, muy presente en su imaginario de futuro.

Aún más, debemos analizar seriamente el denominado "efecto Seúl", la capital de Corea del Sur. Ubicada a $55 \mathrm{~km}$ de la frontera y solo a menos de $200 \mathrm{~km}$ de Pyongyang, Seúl es una "ciudad global", resultado del crecimiento económico conocido como el "Milagro del Río Han".

Es la cuarta economía metropolitana del mundo, con un PIB de 773.900 millones de dólares (toda España supone el 1,1 billón), solo inferior a Tokio, Nueva York y Los Ángeles. Su población es de 10 millones -en la ciudad propiamente dicha- que alcanza los 24,5 millones en el área metropolitana, situándose en la cuarta área metropolitana más grande del mundo ${ }^{26}$.

Por último, el arma nuclear es para Corea del Norte, como lo es para todos los países que la poseen, un elemento de protección pero también "símbolo de estatus", de tal manera que frente a un mundo bipolar en la guerra fría (EE.UU. vs. URSS), hemos pasado a "un mundo multipolar con armas nucleares" con esos dos elementos de protección y estatus, "que lo convierte en mucho más peligroso" (Bracken, 2017).

Por consiguiente, exponemos aquí la primera mentira del mantra ritual: la desnuclearización de Corea del Norte no es posible. Los requisitos previos para ello son excesivos, casi inimaginables. En concreto, una hipotética desnuclearización total requeriría cuanto menos cumplir, para el Norte, las siguientes cuatro condiciones:

» La retirada de tropas de EE.UU. en Corea del Sur y el fin de maniobras conjuntas entre los dos países, que son vistas en términos de agresividad por Pyongyang.

» Una declaración en firme y creíble de los países de la zona y EE.UU. de que el régimen norcoreano no será atacado en ningún supuesto y que se garantiza la seguridad de sus fronteras, su statu quo y la permanencia en el poder de la actual élite.

» La garantía de que en ningún supuesto y bajo ninguna circunstancia, destruido el arsenal nuclear de Corea del Norte, ninguna potencia extranjera, intervendrá militarmente

25 En los últimos años hemos intentado consultar diversas fuentes que pudieran dar datos de compra de material militar por parte de la RPDC en el exterior, sin éxito. En el 2008, un informe confidencial de Corea del Sur, filtrado por un diputado del partido del gobierno en ese momento, indicaba que quizá en un periodo de cinco años (20032008), Corea del Norte habría gastado unos 65 millones de dólares en compra de armamento extranjero, a un ritmo de trece millones al año, para la compra de uniformes, armas automáticas y algunos vehículos militares, a Rusia, China, pero incluso también a Alemania y Eslovaquia.

26 Datos de 2016. Para años anteriores, véase OECD Economic Surveys Korea, june 2014.

\section{Para Corea del norte el arma nuclear es una opción de supervivencia mucho más liviana y de increíble mejor retomo en términos de gasto económico}


contra el país o, aun más, se podrán trabas a su supervivencia, lo que implicaría levantar todas las sanciones internacionales, permitirle un libre comercio con todo el mundo y el flujo interno y externo de divisas.

»Y lo que aún es más, la garantía de que podría desarrollar su ejército convencional -¿por qué no? - y la compra de material moderno a Rusia y China para renovar sus Fuerzas Armadas, porque a ningún país se le puede imponer, en términos de lógica estratégica, que desmantele su programa nuclear y mantenga un ejército convencional desvencijado, quedando así a merced de cualquier interés exterior.

Es muy difícil localizar en los documentos al uso una reflexión que ponga en valor la posición norcoreana; generalmente se defiende la desnuclearización a cambio de garantías y ayuda económica. Esta última se refleja generalmente en alimentos y combustible, pero no se concreta más allá en el primer caso.

Las "garantías", quiérase o no, son garantías para la supervivencia del régimen, un sistema totalitario poco dado a empatizar y que a lo largo de la historia ha demostrado que tiene su propia hoja de ruta y que pese a su "amistad" con la URSS jamás se integró ni en el COMECON ni en el Pacto de Varsovia -y hace gala de ello- y que aún con la amistad y ayuda de China, tampoco Pekín tiene un grado de control absoluto; al contrario, Pyongyang se esfuerza por demostrar que su país no se inclinará ante su gran vecino, como acredita el documento publicado en Rodong Sinmun el 5 de mayo de 2017.

Esta lógica, por lo demás, es muy propia de la historia norcoreana; la RPDC ha sido comunista hasta crear su propio concepto ideológico, la Idea Juche y luego la Idea Songun; pero más que comunista o Juche-Songun, es nacionalista; el discurso de sus líderes es profundamente nacionalista -aunque no se exprese en estos términos-. Y aún más que nacionalista, Corea del Norte es "coreana": una defensa extrema de su identidad propia, quizá fruto de la locura genocida de Japón entre 1910 y 1945, de la guerra intercoreana de 1950-1953 y el permanente bloqueo durante más de 70 años y la creación de una conciencia entre la población que comporta un sentimiento -que hemos contrastado personalmente- de "fortaleza asediada" o en términos militares, de "efecto Masada".

Por ello, a nuestro juicio, existen elementos suficientes para desmantelar el primer mantra repetido hasta la saciedad cual es que forzosamente la RPDC debe desnuclearizarse si desea integrarse en la sociedad internacional. Si a ello lo unimos a que ningún país con armas nucleares tiene intención de suprimirlas y que existe un amplio consenso entre los políticos y militares de los países nucleares y de sus aliados en torno a que la disuasión funciona y sobre la irreversibilidad de los artefactos nucleares (Petrovic, 2017), se hace buena la afirmación del director del laboratorio de Los Álamos, Sthephen M. Younger de que "las armas nucleares no pueden desinventarse”, criterio plenamente asumido por Pyongyang.

A nuestro juicio, la realidad es toda la contraria: la desnuclearización de Corea del Norte es un desiderátum casi imposible y ninguno de los procesos llevados a cabo con anterioridad -como en las conversaciones a seis bandas Six Party Talks ${ }^{27}$, ahora suspendidas- han finalizado con éxito, tanto por la incapacidad del Norte para avanzar como por el ninguneo de los restantes

27 Las Six-Party Talks o Conversaciones a Seis bandas fue un intento iniciado en el 2003 de que los países afectados pudieran encarrilar el problema de la nuclearización de Corea del Norte y si acaso, conseguir su fin, a cambio de cooperación, suministro de alimentos y combustible y otros beneficios para Pyongyang. Las conformaban las dos Coreas, China, Japón, Rusia y EE.UU. Los avances fueron muy escasos y en la actualidad están suspendidas.

ningún país con armas nucleares tiene intención de suprimirlas 
países al no considerar el concepto "nacionalista” de la nuclearización norcoreana y su clarísima vinculación en su estrategia de supervivencia no solo como país independiente, sino como régimen y aún más, como clan o nomenklatura político-social en torno a la familia Kim y los máximos dirigentes civiles y militares del país.

\section{El segundo mantra: el inevitable colapso de la RPDC}

El colapso de Corea del Norte es uno de los mantras más manidos de las tres últimas décadas. Todo ello parte de una reflexión que parece académica y políticamente incuestionable para la inmensa mayoría de investigadores y analistas: la RPDC no ha llegado para quedarse sino que su destino natural es su derrumbe -luego nos referiremos a la reunificación-y además, que este final será tras un colapso de proporciones descomunales.

Casi nadie parece apostar en absoluto por las opciones vitales de Corea del Norte, aunque en los últimos años se abre brecha en ciertos investigadores de que la tesis de la inevitabilidad es errónea, aunque solo sea porque la RPDC cumplirá en el 2018 su 70 aniversario formal, si no tenemos en cuenta el periodo de interregno de 1945-1948. En este pensamiento o mantra, la RPDC es un "cuerpo" asistido con respiración artificial y sin casi señales vitales que debe perecer en cualquier momento y, además, de manera repentina e incluso violenta. Es cierto que durante la existencia de la URSS y el sistema de bloques, nadie cuestionó especialmente la supervivencia de la RPDC.

Ello se vinculaba a la Guerra Fría y a la existencia de una Unión Soviética artificial pero unida, e incluso a una división de Alemania que parecía también irreconducible. El fin del comunismo soviético, la desintegración de la URSS y la absorción de la Alemania Oriental por parte de la RFA conllevó a pensar que un nuevo paradigma se abría paso y que aquellos países que gravitaban en la estela de Moscú debían desaparecer o bien transformarse.

Ayudó a ello a que a finales de la década de los 80, la otra gran potencia -en todos los términoscomunista, China, inició un proceso de reformas que le ha llevado a ser, en la segunda década del siglo XXI una superpotencia en términos económicos y un poder militar progresivo.

El modelo chino de autoritarismo político con una presunta base comunista (o socialista al modelo chino) fue seguido por Vietnam (con la Đổi Mới, la versión vietnamita de la perestroika) y Laos, no quedando ningún vestigio en Asia del modelo maoísta. Solo Corea del Norte no siguió en ese momento ni luego un proceso de reformas como las chinas o la Đổi Mới vietnamita.

Muchos analistas vaticinaron el colapso de la RPDC tras el fin del "Imperio" soviético, una afirmación que se generalizó de manera extensiva cuando Kim Il-sung falleció en julio de 1994. Nadie apostó porque su hijo, Kim Jong-il, al que se calificaba de extravagante, tartamudo, mujeriego, cinéfilo compulsivo y bebedor de coñac francés en cantidades industriales, fuera capaz de sostener el sistema.

Ese traspaso de poder dio pie a multitud de artículos sobre el previsible fin del régimen, aunque algunas voces apuntaron al erróneo cálculo sobre la personalidad del nuevo dirigente, como la secretaria de Estado de EE.UU. Galbraith que lo calificó de especialmente inteligente y en todo caso sobrevivió al colapso de la URSS, las reformas chinas, la gran hambruna de 1994-1998, a diversos presidentes surcoreanos y norteamericanos e incluso se permitió poder transmitir el poder a su hijo, la tercera generación familiar, lo que no está nada mal, de tener en cuenta todas las ineptitudes que se le atribuían. 
Y aunque de nuevo no sucedió -tampoco con el anterior proceso, del fin de la URSS o la liberalización económica de China-, de nuevo se vaticinó el colapso por la hambruna del periodo 1994-1998. Es cierto que fue un periodo excepcionalmente duro, bautizado por la propaganda norcoreana como "Ardua Marcha", pues fallecieron -las cifras reales se desconocen, incluso posiblemente para el propio régimen- entre 800 mil y 3,5 millones de norcoreanos y causó un estrago de salud y supervivencia a los no fallecidos de proporciones casi bíblicas.

En ese periodo, Corea del Norte y su dirigente Kim Jong-il y el régimen mismo estuvieron a punto de desaparecer por un colapso total. O cuanto menos, eso se previó en Europa, EE.UU. y otros países. Sin embargo, la acumulación del fin de la ayuda soviética, el cambio en China, los desastres climáticos en Corea del Norte, la ausencia de comida y una hambruna dantesca no derribaron el régimen.

No se conoce con certeza de esa época levantamiento militar ni intento de golpe de Estado alguno; ni turbulencias en la nomenklatura, ni revueltas ciudadanas ni inestabilidad. Corea del Norte no llegó ni tan siquiera a ser un Estado fallido. Es cierto que proliferó el mercado negro, el régimen perdió el control de una parte de la ciudadanía en cuanto a sus actividades clandestinas o su movilidad, pero la RPDC en absoluto desembocó a un proceso parecido a otras naciones, como ha sucedido en Somalia o Siria. No sin cierta admiración, debemos indicar que el pueblo norcoreano sufrió lo indecible y lo hizo en silencio y los relatos sobre la época demuestran esa dureza y estoicismo ${ }^{28}$.

Fruto del miedo, del compromiso con su país, de un nacionalismo norcoreano que no debemos desdeñar, del amor a la patria que sin duda los coreanos (del Norte y el Sur) mantienen, impulsados quizá también por la propagada y la ideología y por valores propios de su milenaria cultura, como la familia, el apego a la autoridad, la creencia en los valores del "padre" (el de la familia, el líder del país, el jefe de la comunidad) y también galvanizados bajo un concepto de que todos estos sufrimientos eran ajenos a su culpa y creados por factores externos, la ciudadanía -y por extensión, el régimen mismo- de Corea del Norte resistió. La gran hambruna se transformó en lenguaje oficial en la "Ardua Marcha", en un elemento mismo del proceso histórico del país ${ }^{29}$ y Kim Jong-il y su nomenklatura sobrevivieron.

Así, a partir de 1998 el país empezó a salir del coma. Esa salida de la UVI sin embargo no desanimó a los agoreros: se vaticinó de nuevo el colapso por la incapacidad de reformas económicas reales, por no seguir el modelo chino o vietnamita y por el constante drenaje de recursos de la economía en favor del Ejército a unos niveles que sitúan el país en el primer puesto del ranking mundial. Pero pese a todo ello, la RPDC no colapsó.

De nuevo se previó que el régimen finalizaría a partir de la enfermedad de Kim Jong-il. Éste inicia una etapa clara de declive físico en 2008: un aparente fuerte ataque cerebral lo retira de la escena pública en verano y durante meses se teorizó e incluso especuló sobre su muerte. Sin sucesor aparente, no pocos analistas entendieron que el modelo sucesorio de Kim Il-sung a

28 De las biografías de desertores se desprende que, en las zonas rurales, los habitantes recolectaban todo tipo de plantas e hierbas o corteza de los árboles para alimentarse o que el abono de los campos se efectuaba con la obligatoria recogida de las defecaciones de todos los ciudadanos. Algunos analistas relatan casos de canibalismo y también que disminuyó drásticamente el número de matrimonios ante la imposibilidad de alimentar a los hijos.

29 En el Museo de la Revolución de Pyongyang, dedicado a la historia de la RPDC, el periodo de la Ardua Marcha tiene su propio apartado, al mismo nivel que otros periodos específicos, como la lucha contra la ocupación japonesa o la guerra intercoreana de 1950-1953.

\section{Madie apostó porque su hijo, Kim Jong-il, al que se calificaba de extravagante, fuera capaz de sostener el sistema}


Kim Jong-il (que aconteció en 1994) no era posible reproducirse, máxime cuando aquel último había estado a la sombra de su padre al menos durante veinte años ${ }^{30}$. En el 2008, Kim Jong-il no tiene a nadie que le suceda y los análisis más serios vaticinan una lucha por el poder y por tanto, el fin de un modelo.

Es entre 2009 y 2010 que Corea del Norte sorprende al mundo con el anuncio del sucesor: un muchacho joven de 28 o 29 años, desconocido por toda la ciudadanía norcoreana y apenas referenciado en el exterior: Kim Jong-un.

En términos confucionistas, un muchacho soltero menor de 30 años suponía tanto como transmitir el poder a un pájaro fugaz. Se plantearon análisis que vaticinaban que jamás llegaría a gobernar o si lo lograba sería bajo tutela; una tutela que rápidamente pareció residenciarse en el general Jang ${ }^{31}$, esposo de su tía -hermana de Kim Jong-il-, a la cual también se le otorga aparente legitimidad. De hecho, en vida de Kim Jong-il, Jang y su esposa son nombrados generales de 4 estrellas, al igual que el propio Kim Jong-un.

Pocos creían que este modelo de transición fuera eficaz y con garantía de éxito. Y, además, Corea del Norte ingresaba en un periodo oscuro, con un líder terminal y un nuevo dirigente sin ninguna experiencia y quizá con dudosos apoyos entre la nomenklatura militar y civil. De forma repentina -relativamente- Kim Jong-il fallece en diciembre de 2011, esto es, no más de tres años después del anuncio de que su hijo le sucederá.

De nuevo se vaticinó el fin del régimen. La imposibilidad que un país sometido a tanta tensión interna y externa pudiera ser dirigido por el tercero de los Kim, inexperto y joven, permitía de nuevo el futurible final, o cuanto menos una dirigencia basada en el general Jang, en su esposa y un núcleo de militares y miembros del Partido afines al padre fallecido.

Contra pronóstico, Kim Jong-un sobrevivió políticamente -incluido un más que posible golpe de estado en el 2013 que supuso la ejecución de su tío, el general Jang- y en el 2017 ha celebrado el $5^{\circ}$ aniversario de su llegada al poder. A lo largo de este periodo (2012-2017), el general Jang ha sido ejecutado, se ha depurado la estructura de la cúpula militar en numerosas ocasiones y el Partido parece haber renacido y avanzado posiciones como opción "civil" frente a la militarización de la élite de la etapa kimjongilista.

Su núcleo de poder -generalmente desconocido- ya no es el que heredó de su padre, se ha marcado su propia hoja de ruta, ha militarizado mucho más el discurso y ha optado por cambios ideológicos basados en el arma nuclear como principal referente pero vinculada a un nuevo concepto económico, creando una filosofía que calificándose de kimilsungnismo-kimjongilismo -en honor a sus antecesores- plantea el desarrollo del arma nuclear y de la economía al mismo tiempo, retroalimentándose una con otra: la "byungin" o búsqueda simultánea del desarrollo ${ }^{32}$, lo que no impide también sostener que en el 2015 un 30 por ciento de la economía ya podría ser

30 Nombrado sucesor en 1974, inicia su marcha de control político real a partir de 1980 y se extiende su "aprendizaje" hasta 1994, con la muerte de Kim Il-sung en julio de 1994.

31 Véase, al respecto, Boltaina (2014).

32 Se han publicado muchos documentos sobre el "byungjin" pero es difícil de contrastar transcurrido solo un año, la efectividad del modelo. Entre los más recientes, véase Justo, M. (2015). La silenciosa "revolución" económica de Corea del Norte. BBC.com. Recuperado de http://www.bbc.com/mundo/noticias/2015/04/150421_corea_del_ norte_apertura_economia_ao

De nuevo se previó que el régimen finalizaría a partir de la enfermedad de Kim Jong-il 
informal y ajena cuanto menos parcialmente al control del Estado y que supondría la simiente de una "economía dual" de imprevisible evolución ${ }^{33}$.

Por lo demás, Kim Jong-un ha creado una nueva clase dirigente, leal al sistema, "civil" -en el sentido de que muchos de sus integrantes no son solo militares, como sucedió con su padre, sino civiles del Partido- que se asienta en la capital y conforma una nueva élite nada favorable a reformas que puedan suponer el fin del sistema.

Kim Jong-un se siente tan aparentemente firme en el 2016 que tras 26 años convoca un Congreso del Partido del Trabajo de Corea, algo que su padre nunca realizó -el último se celebró en 1980, con Kim Il-sung.

En mayo del 2016 elimina muchos restos del pasado, modifica por segunda vez la Constitución y se proclama "Dirigente Supremo" del país -ya lo era, por lo que reitera su primacía- a través de cambios legales que le atribuyen el cargo de Presidente del Comité de Estado -extinguiendo la Comisión de Defensa Nacional, centro del poder de su padre-, donde aúna el poder militar y civil. Es más, parece que su itinerario supone disminuir el poder del Ejército y otorga más papel al gobernante Partido del Trabajo, del cual es líder absoluto y formalmente indiscutido.

Naturalmente Kim Jong-un no está solo, todo lo contrario, ni las decisiones son tomadas en exclusiva por él, pese a una cierta obsesión de no pocos analistas en plantear una total y absoluta concentración de poder unipersonal y, además, en un dirigente errático, impredecible y psicológicamente desquiciado.

Nada más lejos de la realidad; en este viaje iniciado en el 2011 le acompaña un grupo específico -no siempre el mismo, pues lo ha depurado en diversas ocasiones-, el "core" del sistema -siguiendo la expresión aplicada al actual modelo chino-, una élite de las que muchas de sus figuras no son conocidas o cuanto menos poco relevantes ad extra de los muros palaciegos de Pyongyang, manteniendo un especial papel su propia familia, como su hermana Kim Yo-jong, denominada "estrella ascendente del poder", aunque también Kim Jong-chol, el hermano menor o Kim Sul-song, medio hermana del dirigente.

Así, para Morillot y Malovic (2016) el arte del gobierno de Kim Jong-un reside en el equilibrio entre el Partido y el Ejército, siempre teniendo en cuenta además las ambiciones personales -más allá de los cargos ostentados-y el factor familiar de sus hermanos ${ }^{34}$ y posiblemente de su esposa, Ri Sol-ju.

Sin embargo, el discurso oficial y único lo pronuncia Kim Jong-un y para él seis son las claves del modelo: ninguna reforma de la ideología kimilsungnista-kimjongilista de sus antecesores -verdad a medias-, papel central de las fuerzas armadas, desarrollo del arma nuclear, vinculación del poder militar al desarrollo económico a través del "byungjin” y fortalecimiento del papel del Partido del Trabajo, y todo ello bajo la sexta premisa: independencia política, militar, económica y social a toda costa del país y a cualquier interferencia exterior, incluidas las de China, en una apuesta nacionalista-coreana nada ajena al estilo de su abuelo Kim Il-sung y de su propio padre Kim Jong-il.

33 Hasta el punto de hablarse de la "República de Pyongyang”. Véase Collins (2016).

34 Ellos plantean que Kim Jong-un ha favorecido una nueva élite, del Partido y el Ejército, "sangre nueva” de una generación joven consciente del mundo exterior y menos impregnada de ideología que sus antecesores. Se favorece así a los denominados "príncipes rojos" (bonghwajo), hijos de dirigentes que se han conocido en la escuela o la universidad. Una joven generación que tuvo a su abuelo y a su padre en torno a los de su misma generación y que ahora toman el relevo, rejuveneciendo la élite, como cuestión de supervivencia del propio Kim Jong-un y su familia.

\section{Kim Jong-un ha creado una nueva clase dirigente, que se asienta en la capital y conforma una nueva élite nada favorable a reformas que puedan suponer el fin del sistema}


Llegados al 2017, la RPDC celebrará en el próximo año 2018 el 70 aniversario de su creación forma ${ }^{35}$ y habrá tenido tres únicos máximos líderes, todos ellos de la familia Kim. El sistema no se ha colapsado y no parece, en el momento presente, que pese a las penurias, bloqueo internacional, amenazas militares externas, retórica interna belicista, etc., que el país sea, ya no solo un Estado fallido - en absoluto comparable a Afganistán, Irak, Somalia o Libia- sino un país que pueda preverse su fin como tal Estado.

Una nueva doctrina política ha nacido, y se acumula a la Idea Juche inicial -idea política-y a la Idea Songun -doctrina militar: el kimilsungnismo-kimjongilismo- que proclamado como línea ideológica a partir de 2017, había tenido su primera cita formal en el 2012, en una emulación dentro del comunismo de la expresión "marxismo-leninismo".

A nuestro juicio, el segundo mantra repetido hasta la saciedad de nuevo deviene falso o cuanto menos, incierto y no contrastado. Las razones son muy diversas y posiblemente incluso complejas de perfilar desde una óptica occidental. Un aspecto posible en esta incomprensión es que todos los analistas han dado por supuesto que Corea del Norte está condenada a morir y no han razonado o buscado elementos inversos a esta idea predecidida. Una idea que parte de la existencia de dos Coreas y de la "distorsión” que ello supone.

Es cierto que la historia del siglo XX demuestra que los países divididos han finalizado en su partición. Yemen, Vietnam y Alemania son los ejemplos más relevantes ${ }^{36}$. Pero Corea, un país cinco milenario en la mitología del país, pero cuanto menos bimilenaria según los datos históricos contrastados, no parecía que pudiera existir entre un Norte en caída libre y un Sur como gran potencia económica de Asia -quizá la tercera, tras China y Japón-.

Una gran mayoría de analistas han vaticinado la incapacidad de Corea del Norte de sobrevivir, máxime cuando es un régimen totalitario, aunque quizá ello es una de las claves de la supervivencia.

Los norcoreanos no abjuran de su país -incluso entre los desertores o exiliados, no hay una crítica a su país, sino en todo caso a sus dirigentes, y no a todos, porque pervive un especial respeto por Kim Il-sung, el primero de ellos-; existe un fuerte sentimiento nacionalista coreano, un paradigma completamente diferente a los países árabes que dieron pie a las "primaveras" pues generalmente eran más fieles a su tribu o zona geográfica, algo que en absoluto sucede con los norcoreanos.

Una historia de 70 años que ha unido más de lo que los analistas parecen reconocer, en donde hay una trayectoria vital de las generaciones -guerra antijaponesa, guerra civil con el Sur, años de despegue económico, años de solidaridad o supervivencia tras la década de los 90, el sempiterno "enemigo" exterior- que bien alimentada por la propaganda y la ideología, han unido al país quizá tras sus líderes más de lo que se quiere reconocer.

35 En realidad la Corea comunista nace en 1945. Entre agosto de ese año y septiembre de 1948 estuvo bajo administración soviética y siendo ya primer ministro del país Kim Il-sung. La independencia "formal" acontece en 1948 y por tanto, el 70 aniversario de la RPDC se celebrará en septiembre del 2018, aunque técnicamente el régimen kimilsungnista nació tras la guerra mundial y se extendió hasta 1994, en que toma el poder su hijo Kim Jong-il, tras la muerte de su padre.

36 Alguna anécdota sobrevive, como Chipre, dividido entre la oficial República de Chipre -miembro de la Unión Europea- y la República Turca de Chipre del Norte, solo reconocida por Turquía. Idéntica circunstancia acontece en muchas repúblicas del Cáucaso, secesionadas de sus Estados originarios (Osetia del Norte, Osetia del Sur, Nagorno-Karabaj, etc.) o en Moldava, la rusófila República de Transnitia.

\section{La RPDC celebrará en el próximo año 2018 el 70 aniversario de su creación formal y habrá tenido tres únicos máximos líderes, todos ellos de la familia Kim}


Lo cierto es también que los analistas internacionales han querido atribuir a Corea del Norte males, futuribles o trayectorias hipotéticas que no se predican de otros países.

En primer lugar, dar por supuesto que el modelo norcoreano estaba condenado al bloqueo o al colapso, y posterior desaparición. Era una opción, pero ello no se plantea en Bangladesh, Laos, Papua-Nueva Guinea o incluso en Estados claramente fallidos como Somalia o la República Democrática del Congo. ¿Por qué sí, en cambio, Corea del Norte?

A nuestro juicio, la clave es la existencia de otra Corea, fuerte y pujante, la del Sur. Cualquier referente hacia la RPDC se antepone a Corea del Sur; cualquier elemento económico, político, social, de transformación se mira en el espejo surcoreano, lo que evidentemente en términos occidentales no aguanta la comparativa. Si el Sur no existiera, ningún analista predeciría el colapso, como sucede en otros muchos países de Asia, que son auténticos Estados fallidos o aún más en el supuesto de África ${ }^{37}$.

En segundo término, porque se ha extrapolado el desastre de funcionamiento del modelo comunista y el fin de todos los sistemas de este modo, a Corea del Norte. Se ha olvidado, sin embargo, que Corea es menos "comunista" que nacionalista - en la práctica se califica como país del Juche, la ideología oficial y no hay referencias al comunismo-, y menos nacionalista que "coreana". El paradigma norcoreano no podía ser analizado bajo el prisma europeo o incluso chino. Hay modelos tan ineficientes como el norcoreano, en el ámbito económico, y nadie cuestiona su viabilidad, como Camboya o Laos, por ejemplo.

En tercer lugar, porque muchos análisis han confundido los deseos con la realidad. Corea del Norte ha sido calificado de "état voyou"38, estado terrorista -fue incluido en el "Eje del Mal"39 por George W. Bush y luego retirado de la lista-, satrapía gobernado por un "loco", estado fallido, "último régimen estalinista", "rogue state"40 "reino ermitaño" y a sus dirigentes, se les ha atribuido de todo tipo de enfermedades mentales y físicas, desconociendo que en ningún país solo hay una única persona gobernando y que la nomenklatura norcoreana había sabido sobrevivir a décadas y más décadas de adversidades.

En este sentido, Kim Il-sung nació como dirigente con Stalin y sobrevivió a Krushev -del que fue muy crítico-, a Brezhnev y a los sucesivos dirigentes de la URSS e incluso más allá del fin de la Unión Soviética; su hijo Kim Jong-il llegó al poder tras el fin de Gorbachov y con Yelsin en el poder y falleció gobernando Putin en el Kremlin. Su hijo Kim Jong-un, con solo cinco años en el ejercicio del mando, ha visto a Obama y Donald Trump en la Casa Blanca pero aún más significativo, a tres presidentes surcoreanos: el presidente Lee Myun-bak, la presidenta -imputada y procesada- Park Geun-hye y desde 2017 el Presidente Moon Jae-in.

37 África es un buen elemento comparativo porque muchos países fueron construidos a golpe de “cartabón”, con fronteras artificiales (Malí, Burkina Faso, Chad), o divisiones entre diversos países de igual nombre (GuineaBissau, Guinea Ecuatorial, Guinea-Conakry; los diversos Congos) o países minúsculos rodeados por la gran potencia surafricana, como Malawi, Swazilandia o Lesotho.

38 Término acuñado por Rigoulot, P. (2007). La Coree du Nord, état voyou. París: Buchet Chastel.

39 La inclusión de Corea del Norte parece ser que fue efectuada contra toda lógica, habida cuenta que ninguna relación guardaba con el terrorismo islamista, más bien lo contrario, y no pocas fuentes indican que se incluyó para que fueran tres y no dos los Estados: Irak, Iran y Corea del Norte. Apenas unos meses antes de la elección de Barack Obama fue suprimida tal calificación (octubre de 2008).

40 Véase Triplett (2004). 
Finalmente, no puede negarse que los indicadores económicos y sociales de la RPDC no apuntan a progresos palpables, pero tampoco ya son negativos, por lo que la predicción del colapso económico empieza a ser ambivalente.

El crecimiento es muy lento, pero es existente, pese a que muchos análisis indican que existe un grave problema de corrupción ${ }^{41}$ y la ayuda internacional ha disminuido en gran medida; las reformas económicas no avanzan al ritmo necesario pero existe un cierto campo a la economía informal que parece crecer año tras año; el país sigue profundamente ideologizado, en un contexto internacional permanentemente al "límite" y, para la inmensa mayoría de los espectadores, es un país que puede entrar en guerra con EE.UU. o con el Sur en cualquier momento o puede sufrir un ataque militar exterior, lo que vaticinaría el colapso, pero el día a día de la ciudadanía parece aparentemente tranquilo, la capital Pyongyang se ha renovado y continúa siendo un símbolo de estatus, y la hambruna de los años 90 en las zonas rurales ha desaparecido, lo que produce una contradicción evidente al visitante, si compara la situación interna in situ con las noticias en los medios de comunicación internacionales.

Por otro lado, desde 1953 la RPDC no ha participado en ninguna guerra y lo que aún es más, cuando EE.UU. ha intentado atacar limitadamente el territorio norcoreano -proyecto del presidente Clinton de 1993- el propio Sur lo evitó, de la misma manera que en la actualidad (2017) el temor del colapso por parte de China y Corea del Sur, a partes iguales, evita quizá ese mismo colapso.

El segundo mantra ha derivado, a nuestro juicio, en igualmente falso y sin paliativos. Tras casi tres décadas previendo el fin de la RPDC, ella permanece relativamente impasible en un camino hacia un futuro absolutamente imprevisible, pero en el que no parece que el fin del mismo -si es que se da- sea el colapso del sistema, una revolución interna, el levantamiento de su ciudadanía emulando las primaveras árabes o un golpe militar o guerra civil interna que disgregue el país y aún menos - pese a lo que parece- un ataque militar exterior, que situaría a la zona de mayor crecimiento y poder económico de Asia en el siglo XXI (China, Japón, Corea del Sur, Hong Kong, Taiwán) en una hecatombe económica cuya recuperación podría suponer un largo gólgota de diversas décadas.

Precisamente, en esta hipótesis de colapso uno de los argumentos más mencionados es el fin del régimen a través de un enfrentamiento bélico, supuesto especialmente mencionado tras la llegada al poder de Donald Trump. En el periodo febrero-mayo del 2017 ese riesgo ha sido asumido por muchos como algo casi inevitable, lo que significaría el fin del régimen, al igual que aconteció en Libia o Irak.

Sin embargo, los datos permiten desmentir cualquier tipo de guerra contra Corea del Norte, por la catástrofe consiguiente, que bien conocida es por los analistas y militares. En concreto aunque la nueva Administración Trump se refiere a Corea del Norte como un grave problema

41 El analista Julian Robinson se hacía eco de informes de principios del 2017 según los cuales los tres estados más corruptos del planeta en el 2016 habían sido Sudan del Sur, Somalia y Corea del Norte; mailonline, 25-1-2016, según el índice de corrupción que publica Transparency International.

Vid., http://www.dailymail.co.uk/news/article-4155508/World-s-corrupt-countries-revealed.html. A nuestro juicio, la comparación no es asumible, por experiencia propia y porque es imposible determinar el índice de corrupción de un país como Corea del Norte del que se desconoce todo tipo de estadísticas, su nivel económico, su PIB o cualquier otro dato contrastable. Según Transparency Internacional, sin embargo, en Asia solo Afganistán (2016) se emularía a Corea.

Vid. https://www.transparency.org/news/feature/corruption_perceptions_index_2016 última consulta, 20-5-2017.

\section{Los indicadores económicos y sociales de la RPDC no apuntan a progresos palpables, pero tampoco son negativos, por 10 que la predicción del colapso económico empieza a ser ambivalente}


mundial a resolver, parece que se ha llegado, una vez más, a idéntica conclusión que Nixon, Clinton y Bush: un ataque militar contra la RPDC provocaría tal devastación en los países aliados e incluso China que no es una opción real, y ello es conocido por el régimen norcoreano.

Es más, aun sin recurrir a armamento nuclear o de destrucción masiva, un primer enfrentamiento supondría que Seúl, la capital surcoreana, padecería en el primer momento unas bajas de más de 64.000 muertos $^{42}$; el analista Joseph Bermudez indica que en 45 segundos los cohetes norcoreanos alcanzarían el territorio del Sur.

A la inversa, un ataque preventivo contra Pyongyang es difícilmente practicable. En el informe de R. Cavazos (2017), se calcula que el Sur lograría eliminar la artillería norcoreana a un ritmo del 1 por ciento cada hora, pero en el supuesto de flaquear la RPDC y ante el inmediato colapso militar, muchos son los que creen que el régimen recurriera al armamento no convencional.

Los servicios de inteligencia occidentales y asiáticos consideran que la RPDC posee uno de los arsenales químicos mayores del mundo, un programa propio de armas biológicas, un departamento altamente cualificado para la ciberguerra y entre 10 y 25 ingenios nucleares. En este enfrentamiento, miles de víctimas de la capital del Sur serían chinas, pues son el 70 por ciento de los extranjeros que residen en Seúl. Por ello, China es también uno de los principales interesados en que no haya escalada militar, tanto por lo que supondría a sus nacionales como por la previsible huida de cientos de miles norcoreanos a través de la frontera norte del país.

En esta hipótesis de colapso uno de los argumentos más mencionados es el fin del régimen a través de un enfrentamiento bélico

A nuestro juicio, el mantra ha resultado falso o cuanto menos erróneo. Corea del Norte no colapsará. Y si corre el riesgo de que suceda, es tan peligrosa la hipótesis que los países de la zona, incluido sus "enemigos", intentarán evitarlo.

El statu quo actual es el mejor elemento para que todos puedan seguir con su progreso económico actual, lejos de aventuras y gastos económicos para ayudar a una Corea del Norte hundida.

\section{El tercer mantra: la reunificación/absorción del norte por parte del Sur}

No hemos referido en este encabezamiento del apartado como la "reunificación" sino un concepto distinto, muy similar a lo realmente acontecido en el caso de Alemania: Corea del Norte será absorbida por el Sur en un proceso en donde habrá un ganador y un perdedor.

Posiblemente es el mantra más común, aceptado, incuestionable e inequívoco, formalmente defendido por analistas, investigadores, políticos y la propia dirigencia coreana, incluida la del Norte, si bien en este caso no se plantea en modo alguno como lo hace el Sur y EE.UU.

El futuro solo puede pasar por una sola Corea, unificada. Así, este mismo es el mensaje de Pyongyang ya anunciado en 1970 por Kim Il-sung y prueba de ello en el Sur es la existencia de un Ministerio para la Reunificación. Por tanto, en este mantra la afirmación es clara e irreversible: la RPDC desaparecerá y surgirá una sola Corea, única y unida.

El mantra, sin embargo, tiene algunas características asumidas por casi todos los analistas y políticos, con la excepción -claro está- de Corea del Norte, que parece -dicho con ironía- que

42 Informe del experto militar R. Cavazos, citado por www.elconfidencial.com; 26-4-2017. Este autor ya ya planteaba muchos escenarios interesantes en Cabazos (2012). 
en este debate nada tenga que decir, salvo que también pretende la reunificación, pero según sus reglas, fijadas en el su momento por Kim Il-sung: confederación y paridad.

En este análisis, que no compartimos, la reunificación del Norte y el Sur debe pasar, "inevitablemente", por tres paradigmas teóricamente incuestionables:

a) La reunificación supondrá el fin del modelo de la familia Kim y la reunificación de la península bajo un único modelo, triunfante e imperante, que es el del Sur. Nadie cuestiona esta "verdad" - excepto el Norte, por supuesto, pero ello no parece que merezca ninguna credibilidad, para la mayoría de investigadores y analistas-. Habrá una nueva Corea, que será capitalista, democrática y gobernada según las reglas del régimen de Seúl.

b) El segundo elemento es que en esta reunificación habrá un claro y único perdedor, el Norte, y un vencedor: el Sur y sus países aliados. Es más, los analistas que prevén dificultades para la reunificación parten de la base que una dificultad es la posición de China, que no aceptará fácilmente que una Corea capitalista y aliada de EE.UU. llegue hasta sus fronteras, y que permanezcan tropas norteamericanas en el portal del gran país asiático, pero en absoluto se tiene en cuenta la voluntad de Pyongyang de no ceder ni un ápice en sus exigencias, que son descartadas de antemano.

c) Igualmente, se vaticina que la reunificación será extraordinariamente costosa, difícil de asumir por el Sur, que deberá contar con ayuda exterior de China, EE.UU. y la Unión Europea, e incluso Japón, ya que el Norte será incapaz de adaptarse por sí solo, ni tan siquiera siguiendo el modelo alemán.

En este sentido, muchos análisis han querido comparar el posible modelo de reunificación entre el Este y Oeste de Alemania y el resultado es negativo en todos los supuestos ${ }^{43}$. Se considera que la diferencia entre Norte y Sur es tan abismal y la separación tan profunda en todos los ámbitos, que el coste económico, político, social y militar es casi inasumible -en el caso de Alemania, la desproporción era de 1 a 10; en el caso de las dos Coreas es de 1 a 40-, lo que implicará que Corea del Sur impondrá sus condiciones, el Norte deberá aceptarlas sin ninguna opción de transacción y el modelo norcoreano desaparecerá para siempre.

d) Como corolario, muchos análisis vaticinan una transición para la ciudadanía del Norte muy penosa. Una generación a partir de los 40 años perdida para siempre por su incapacidad para adaptarse al modelo del Sur, solo los adolescentes y los jóvenes hasta los 30-35 años podrían integrarse en una nueva Corea.

Deberían pasar dos o tres generaciones hasta que unos y otros fueran idénticos y así se sintieran; mientras tanto, el Norte se convertiría en una fuente de mano de obra barata que a cambio de parasitar con subsidios y ayudas a favor de los ya no incorporables al mercado de trabajo o los jubilados, vendería su mano de obra a un escaso precio, en favor de corporaciones del Sur, Japón y EE.UU., o la misma China, ante la incapacidad de competir en ningún terreno económico, intelectual, industrial o académico.

En este panorama, Corea del Norte se muestra como un país post-totalitario con una ciudadanía desestructurada e incapaz de adaptarse y un Sur que deberá tutelar el cambio.

43 Por todos, rechazando que el modelo alemán sea extrapolable. Véanse Yang (2016) y Frank (2016). 
e) Aún más relevante, en este paradigma, incluso se plantea que el proceso de reunificación durará años o incluso décadas -veinte años es la cifra más aceptada-, con una Corea del Norte formalmente independiente cual estado títere del Sur, para evitar que un proceso a la alemana rápido y bastante igualitario -recuérdese que el cambio del marco RDA fue de equivalencia a un marco RFA-, pudiera hacer quebrar a Corea del Sur. Los datos más creíbles parecen indicar que el coste económico sería de unos 500.000 millones de dólares, a lo largo de veinte años ${ }^{44}$. Morillot y Malovic (2016) se refieren a cifras que oscilan entre 200 y 500 mil millones de dólares durante treinta años. El Instituto coreano para la Unificación Nacional estimó, en el 2011, que solo el coste inicial de la integración oscilaría entre 35.600 y 161.000 millones de euros, calculados para el primer año y en un proceso de real reunificación a lo largo también de veinte años.

A ello se une el poco o nulo interés de la ciudadanía del Sur por una reunificación "patriótica" con el Norte y el desdén hacia los "atrasados" ciudadanos del Norte, que reproduciría con más fuerza incluso la distinción relativamente xenófoba entre unos y otros ${ }^{45}$.

En este sentido, el referente alemán es claro. Desde 1989 hasta hoy, y pese a los intentos de igualación -como el ejemplo del Ostmarkt y el Deutschmark y los salarios nominales-, los Lander orientales se despoblaron y su industrialización fue lenta, persistiendo dos décadas después una distinción mental entre los Ossies y los Wessies (alemanes de origen oriental y occidental, respectivamente) según el cual los primeros son miedosos, poco ambiciosos, insatisfechos y desconfiados, y los segundos son arrogantes, codiciosos y superficiales ${ }^{46}$.

Este modelo, sin duda, se da por supuesto que acontecerá en una Corea reunificada, en donde la diferencia entre la ciudadanía del Norte y del Sur es, al 2017, infinitamente más rotunda en todos los términos y conceptos, que la existente entre alemanes orientales y occidentales en 1989, y así lo acreditan los norcoreanos que se exilian en el Sur tras huir de su país, con una alta tasa de deseo de retornar a su país de origen.

Por todo lo expuesto, ¿cuál es la razón por la cual el Norte debe aceptar la reunificación cual inevitable hoja de ruta de este mantra y, además, ser la perdedora en el proceso?

Sin entrar en cuestiones estrictamente de política formal -los dos países buscan la reunificación y hacen constantes proclamas a favor de ello-, Corea del Norte no puede aceptar la reunificación en los términos que sucedió en Alemania; esta negativa partirá y se mantendrá siempre desde la nomenklatura de Pyongyang.

a) La reunificación no es factible en términos de igualdad; el modelo económico del Sur es exitoso y escasamente aceptable por la dirigencia norcoreana; los valores sociales y económicos del Sur no se parecen en nada al Norte.

\section{Se plantea que el proceso de reunificación durará años o incluso décadas, con una Corea del norte formalmente independiente cual estado títere del Sur}


La RPDC, además, mantiene unas fuerzas armadas de 1,1 millón de efectivos, que no podrían integrarse -o muy difícilmente- en un Ejército unificado gobernado por oficiales y generales del Sur, que ya no tendría enemigo posible, excepto preventivamente el "enemigo" chino que se situaría en la misma nueva frontera.

La nomenklatura civil y militar norcoreana difícilmente podría adaptarse a la reunificación. No es el modelo postsoviético de reconversión de los antiguos dirigentes a la nueva clase de negocios y funcionarial, porque el envite de las empresas del Sur supondría la "colonización" del Norte ante el empuje de la economía y las empresas de Corea del Sur.

b) El discurso oficial del Norte aboga por la reunificación, pero manteniendo los dos modelos. Así se ha expresado el propio Kim Jong-un, donde parece defender el ideal diseñado por su abuelo, la Republica Confederal de Koryo. Un modelo con sistemas económicos y políticos diferenciados, y además paritarios.

Pero esta opción debería, además, garantizar inmunidad a la nomenklatura del Norte, ningún tipo de persecución penal y además, integración de toda ella en un status quo económico y social ahora imposible. Demasiadas exigencias para una "reunificación” voluntaria.

c) Los analistas, por lo tanto, solo plantean un escenario reunificador factible: el posterior al hundimiento de la RPDC mediante colapso o la reunificación forzosa. Así se barajan supuestos tales como el colapso económico y el hundimiento del control interno, un golpe militar que diera pie luego a la descomposición política y descontrol/control del país, el fin del apoyo chino y el consiguiente hundimiento cual castillo de naipes o un ataque militar limitado del Norte o el Sur que ocasionara el inicio de la descomposición del régimen y la caída rápida, algo que es más un desiderátum que una realidad.

La literatura sobre el "colapso" es abundante y prolija, destacando en los últimos años el trabajo de Bruce W. Bennet (2013), o Ken Gause, en su más reciente (2015) House of Cards, a modo de ejemplo, pero siendo ya muy extensa y siempre errónea en sus predicciones -hasta el momento-, lo que permite a algunos autores ya plantear seriamente el rechazo a la idea y la aceptación de ser un paradigma superado, como en los interesantes documentos de Chad O'Carroll (2014) y Tim Beal (2016).

Beal (2016) se refiere a recientes declaraciones del consultor en temas coreanos y profesor Foster-Carter que considera -irónicamente- que con la edad ha alcanzado la sabiduría y que postula que es preciso finalizar con este mantra "nonsense" a la vez que efectúa un interesante recorrido sobre las predicciones fracasadas y la necesidad de superar la obsesión por el colapso ${ }^{47}$.

Morillot y Malovic (2016) se refieren a la reunificación como un "sueño compartido" que ha derivado hoy en un "mito", hasta el punto que los surcoreanos se sienten como "hermanos de sangre" pero perciben a Corea del Norte como un país extranjero, imposible de vivir bajo una misma bandera.

47 La opinión de once desertores aparecen en O'Carroll (2014). Por lo general los exiliados ("defectors") no parecen convencidos del colapso. Destacaremos a la profesora Hyun que afirma que solo un golpe militar en la élite puede implicar un cambio real; Hong Soon-Kyung indica que solo son factibles cambios graduales; Joo Sung-ha afirma que cualquier cosa puede suceder pero no es aconsejable subestimar la capacidad del régimen; Oh Sehyok asegura que solo el ejecutado general Jang era la persona capaz de reformar el régimen y a la vez unificar la nomenklatura; Kang Jimin se refiere a una capacidad de supervivencia de 5 a 10 años; Koh Nayoung afirma que mientras el apoyo chino subsista, la RPDC sobrevivirá.

Corea del norte no puede aceptar la reunificación en los términos que sucedió en Alemania 
Esto es, la reunificación factible pasa siempre por el segundo mantra que nos hemos atrevido a desdeñar: el colapso de la RPDC.

Acaso quizá haya otras fórmulas. Una "reunificación” lenta, manteniendo los dos Estados independientes, bajo el apoyo de EE.UU., China, Japón, Rusia e incluso la Unión Europea, dando garantías al Norte de un tránsito lento y sin violencia ni represalias, invirtiendo en la RPDC como proceso progresivo para que en dos o tres generaciones la reunificación fuera factible.

Un escenario por tanto que requiere el acuerdo de diversos países que deberían obtener algún beneficio y sobre todo, la propia anuencia del régimen de Pyongyang -que algo debería decir pese a que los analistas se empeñan en no tener en cuenta-, para así plantear un final quizá exitoso hacia el 2040, década que algunos analistas han predicho como el final del camino, dado que la propia Corea del Sur prevé unos veinte años para encarrilar el proceso reunificador "pacífico". Claro está que fracasadas todas las predicciones hechas desde 1990, proponer una fecha es a todas luces absurdo.

A nuestro juicio, por tanto, la reunificación es un mantra inverosímil en el momento presente.

Quizá este lugar común tan constante de la reunificación debería partir de una premisa que incluso podría ayudar a largo plazo a plantear algún modo de unidad, y es que hoy por hoy, la RPDC ha venido para quedarse, que las dos Coreas pueden coexistir, que los modelos comparados del Yemen, Vietnam y Alemania no deben ser necesariamente los únicos y que al igual que hay países divididos a pesar de su unicidad lingüística o étnica -por ejemplo, la existencia de una Alemania, Austria y una Suiza alemana que nadie cuestiona o Rumania y Moldavia-, cualquier aproximación a un cambio debe pasar por reconocer a Corea del Norte a su derecho a existir, pese a que su régimen político produzca en muchos desagrado y en el desiderátum del "mundo de las ideas", Corea debiera ser solo una.

\section{A modo de conclusión}

Nuestra reflexión, a la vista de los antecedentes históricos de la península coreana y la evolución de la RPDC desde 1948 nos permite establecer la falsedad, o cuanto menos la relativización profunda, de los tres mantras mencionados. Ni desnuclearización, ni colapso, ni reunificación.

Corea del Norte seguirá con su programa de nuclearización no solo por razones estrictamente militares, sino por factores económicos y políticos, fundamentalmente.

Por un lado, porque supone mantener su potencial militar disuasorio en términos de gasto mucho más inferior que un Ejército convencional y, sobre todo también, porque políticamente es la garantía de supervivencia del régimen para evitar un ataque exterior o una situación de Estado fallido producido por una intervención extranjera, a la vez que mantenerse como una voz que no puede ser en absoluto desconsiderada sino, al contrario, tenida forzosamente en cuenta.

El nacionalismo nuclear norcoreano da réditos internos al régimen y obliga a los EE.UU., en especial, a repensar sus políticas; aún más, las sucesivas sanciones internacionales contra el país refuerzan este "nacionalismo nuclear del régimen" e incluso otorga una impronta propia del país, lo que la doctrina militar francesa ha calificado "marqueur identitaire" (Péron-Doise, 2016), absolutamente sorprendente para un país con el PIB antes mencionado.

En segundo lugar, el colapso de Corea del Norte -aun sin poderse desdeñar completamente- es una perspectiva que tras décadas de reiteración, no parece ya factible tan fácilmente, salvo que

\section{Acaso quizá haya otras fórmulas: una "reunificación" lenta, manteniendo los dos Estados independientes, bajo el apoyo de EE.UU., China, Japón, Rusia e incluso la Unión Europea}


evidentemente desde el exterior - especialmente China- se decida de manera clara e irreversible a poner fin a la República norcoreana. En caso contrario, no hay elementos que permitan, de nuevo, predecir este colapso y el último elemento -la juventud del nuevo líder, la ausencia de apoyo interior y la ausencia de legitimidad- han derivado en falsos referentes que no se han concretado.

Finalmente, la reunificación no se ha planteado de manera seria y rigurosa en un panorama tan especial. Corea del Norte cuenta con 24 millones de habitantes y por tanto no es una negociación al uso como la del Chipre turco. Supone además la mitad de la población de Corea del Sur, lo cual no es equivalente a lo que sucedió con Alemania. Las diferencias económicas son, además, mucho más exageradas y por tanto, la cuesta arriba es mucho más acentuada.

Corea del Norte tiene su propia personalidad en la esfera interna y externa, y guste o no, ya son más de cuatro generaciones de ciudadanos los que han conocido una única realidad. Quizá ya estemos al inicio de la quinta generación nacida bajo la RPDC.

En el momento presente, solo los norcoreanos de más de 73 años (en 2017) habrían nacido bajo la existencia de un sistema anterior al de la familia Kim y este recuerdo se remontaría al periodo colonial de ocupación japonesa. De hecho, desde 1910 a 1945 Corea fue salvajemente ocupada por Japón y luego una guerra de liberación y una guerra civil permitieron establecer un recuerdo muy específico que construye una identidad colectiva propia norcoreana, difícil de destruir en poco tiempo. Habría que acudir a un norcoreano que superase los 110 años para que hubiera nacido antes de la ocupación japonesa. No existe, por tanto, memoria histórica diferente al régimen del Partido del Trabajo y de la dinastía Kim.

Muy posiblemente, por tanto, la RPDC es un Estado que ha venido para quedarse, tal como hemos afirmado, y hay que tener en cuenta que la posible reunificación no es un desiderátum obligatorio e incuestionable, sino una opción, una más y no necesariamente la más factible ni la mejor.

Una Corea del Norte con reformas en marcha, que progresivamente se adapte al siglo XXI podría perfectamente ser una de las dos Coreas del panorama internacional sin que su futuro pase, necesariamente, como reiteran cientos y cientos de documentos y monografías, por una sola Corea, una unidad que con el paso del tiempo se aleja, pues ya en el 2010 se cumplió el centenario de la ocupación japonesa y en el 2045 se cumplirán los cien años de la división entre el Norte y el Sur, lo que supone el nacimiento de identidades nacionales diferentes y proyectos colectivos también distintos.

Como hemos dicho, a fin de cuentas nadie plantea hoy seriamente la reunificación de Alemania y Austria, de Rumania y Moldova e incluso las dificultades para la reunificación de Chipre -dividido tan "solo" desde 1973- son tan insuperables que solo bajo la fórmula de auténtica confederación parece mínimamente posible y máxime cuando hay tendencias internas de segregación en países centenariamente unidos, como es el caso de Bélgica, Canadá, Reino Unido o España, como ejemplos de que los modelos pretéritos no condicionan las soluciones del futuro. A nuestro juicio, el pasado histórico no sirve para predecir el futuro histórico coreano y los ejemplos de referencia olvidan muchos referentes específicos del especial, ad hoc y singular paradigma norcoreano. 


\section{Bibliografía}

Beal, T. (2006). It's time to stop trying to predict North Korea's collapse. NK News. Recuperado de www.nk.news.org.

Bennet, B. W. (2013). Preparing for the possibility of North Korean collapse. RAND Corporation. Recuperado de http:/www.rand.org/content/dam/rand/pubs/research_reports/ RR300/RR331/RAND_RR331.pdf

Boltaina, X. (2014, 10 de febrero). Diciembre rojo en Corea del Norte: diez puntos clave y diez conclusiones sobre la ejecución del general Jang Song-thae. Documento marco num.3/2014, Instituto Español de Estudios Estratégicos-Ministerio de Defensa. Recuperado de http://www.ieee.es/Galerias/fichero/docs_marco/2014/DIEEEM03-2014_CoreaNorte_DiciembreRojo_BoltainaBosch.pdf

Bracken, P. (1993). Nuclear weapons and State in North Korea. Survival 35(3), 137-153.

Bracken, P. (2017). Fire in the East. En Petrovic, M., La Marcha atrás nuclear. El País.

Cao de Benós, A. (2013). Alma Roja, sangre azul. Editorial Base Hispánica.

Cavazos, R. (2012, 26 de junio). Mind the Gap between rhetoric and reality. Nautilius Institute. Recuperado de http://nautilus.org/napsnet/napsnet-special-reports/mind-the-gapbetween-rhetoric-and-reality/

Collins, R. (2016). Pyongyang Republic. HRNK. Committee for Human Rights in North Korea. Washington. Recuperado de https:/www.hrnk.org/uploads/pdfs/Collins_PyongyangRepublic_FINAL_WEB.pdf

Deane, M. J. (s.f.). The collapse of North Korea: a prospect to celebrate or fear. John Hopkins University. Recuperado de http://www.jhuapl.edu/ourwork/nsa/papers/NorthKorea.pdf

Delisle, G. (2013). Pyongyang. Editorial Astiberri.

Fifield, A. (2016, 8 de mayo). North Korea announces five-year economic plan, its first since the 1980s. The Washington Post.

Frank, R. (2016). The Unification cases of Germany and Korea: a dangerous comparison. USKorea Institute at SAIS. Recuperado de: http://38north.org/2016/12/rfrank120816/ (primera parte); y http://38north.org/2016/11/rfrank1 10316/ (segunda parte).

Gause, K. (2015). North Korean House of Cards: leadership dynamics under Kim Jong-un. HRNK. Recuperado de https://www.hrnk.org/uploads/pdfs/HRNK_Gause_NKHOC_FINAL.pdf

Halberstam, D. (2007). The coldest winter: America and the Korean War. Hachette books.

Halberstam, D. (2008). La guerra olvidada: historia de la guerra de Corea. Editorial Crítica.

Harden, B. (2014). Evasión del campo 14. Editorial Kailas.

Kim, R. E. (2014). Los mártires de Pyongyang. Editorial Sajalin.

Kim, S. (2015). Sin ti no hay nosotros. Ediciones Blackie.

Kim, Y. \& Jung, T. (2016). Status of Social Economy development in Seoul. A case study of Seoul. GSEF Social Economy Policy Guidebook. Recuperado de http://neweconomy.net/sites/ default/files/status\%20of\%20social\%20economy\%20development $\% 20 \mathrm{in} \% 20$ seoul.pdf 
Lee, E. (2011). El mundo es más grande ahora: mi cautiverio en Corea del Norte. Editorial Rialp.

Lee, H. (2015). La chica de los siete nombres: la historia de una huida de Corea del Norte. Ediciones Península.

Mateos, R. (2008). El país del presidente eterno: crónica de un viaje a Corea del Norte. Editorial Milenio.

Morillot, J. \& Malovic, D. (2016). La Corée du Nord en 100 questions. París: Tallandier.

Nurnus, M. \& Van Beek, M. A. (2017). North Korea in the European press: an analysis of stereotypes in British, French and German newspapers. Yonsei Journal of International Studies.

O'Carroll, C. (2014). How long until North Korea collapses? Eleven defector perspectives. NK News. Recuperado de www.nk.news.org.

Office of the Secretary of Defense. (2015). Military and security developments involving the DPR of Korea. Annual Report to Congress. Recuperado de https://www.defense.gov/ Portals/1/Documents/pubs/Military_and_Security_Developments_Involving_the_Democratic_Peoples_Republic_of_Korea_2015.PDF

Park. Y. (2017). Escapar para vivir: el viaje de una joven norcoreana hacia la libertad. Editorial Plataforma.

Petrovic, M. (2017, 21 de mayo). La Marcha atrás nuclear. El País.

Pitarch, B. (2012). Cerrado 24 horas: crónica de un viaje a Corea del Norte. Editorial Leartes.

Rees, L. (2009). El holocausto asiático: los crímenes japoneses en la segunda guerra mundial. Editorial Crítica.

Stares, P.B. \& Wit, J.S. (2009, enero). Preparing for Sudden Change in North Korea. Council Special Report, nr. 42.

Toman, O. (2016, 30 de noviembre). North Korea’s byunginline will succeed. NK News. Recuperado de www.nk.news.org.

Triplett, W. C. (2004). Rogue State: How a muclear North Korea threatens America. Regnery Publ.

Wizenberg, D. \& Varsavsky, J. (2016). Dos caras de una misma Corea. Ediciones Clave intelectual.

Yang, C. S. (2016). Why German Unification is not a model for Korean unification. US-Korea Institute at SAIS. Recuperado de http://38north.org/2016/05/cyang052516/ 